\title{
Photocatalytic degradation of volatile chlorinated organic compounds with ozone addition
}

\author{
Hossein Ebrahimi ${ }^{1}$, Farshid Ghorbani Shahna ${ }^{2 *}$, Abdulrahman Bahrami ${ }^{2}$, \\ Babak Jaleh ${ }^{3}$, Kamal ad-Din Abedi ${ }^{4,5}$ \\ ${ }^{1}$ Iran University of Medical Sciences, Iran \\ School of Public Health, Department of Occupational Health \\ ${ }^{2}$ Hamadan University of Medical Sciences, Iran \\ School of Public Health, Center of Excellence for Occupational Health and Research Center for Health Science \\ ${ }^{3}$ Bu-Ali Sina University, Iran \\ Faculty of Science, Department of Physics \\ ${ }^{4}$ Kurdistan University of Medical Sciences, Iran \\ Environmental Health Research Center \\ ${ }^{5}$ Kurdistan University of Medical Sciences, Iran \\ Department of Occupational Health Engineering, Faculty of Health \\ *Corresponding author's e-mail: fghorbani@umsha.ac.ir
}

Keywords: Photocatalytic oxidation, ozonation, chloroform, chlorobenzene.

\begin{abstract}
The decomposition of hydrocarbons using combined advanced oxidation methods is largely considered owing to abundant production of $\mathrm{OH}$ radicals and the potential economic advantages. In this study, the synergetic effect of ozonation on photocatalytic oxidation of chloroform and chlorobenzene over expanded graphite$-\mathrm{TiO}_{2} \& \mathrm{ZnO}$ Nano composite was investigated. The effect of introduced ozone concentration and residence time was also examined on removal efficiency. The results showed that the removal efficiency was significantly enhanced by the combined system resulting from the additional oxidation process causing active species to be increased. Increasing the introduced ozone concentration which generates more reactive compounds had a greater effect on the removal efficiency than that of residence time. However, from the mineralization point of view, the residence time had a dominant effect, and the selectivity towards $\mathrm{CO}_{2}$ was dramatically declined when the flow rate increased. Based on these results, the combined system is preferred due to higher removal efficiency and complete mineralization.
\end{abstract}

\section{Introduction}

Advanced oxidation processes (AOPs) have recently attracted much attention due to their higher ability in mineralizing of volatile organic compounds (VOCs). Among all effective methods, photocatalytic oxidation (PCO) emerged as a promising method to degrade resistant compounds and transform these chemicals to less toxic products. This method includes the formation of UV-induced electron and hole couples and generation of hydroxyl radicals $\left(\mathrm{OH}^{\circ}\right)$ (Liu et al. 2006)( Verma et al. 2013).

Owing to its simplicity, being under control and classifying as a green process, photocatalysis is a very fascinating technology. Nevertheless, it has a number of problems and disadvantages such as catalyst deactivation, and the creation of harmful intermediates and byproducts. Irreversible deactivation of the catalyst in the case of indole, pyrrole and decamethyltetrasiloxane has been reported. It has also been discovered that the reaction at room temperature leads to rapid deactivation of the $\mathrm{TiO}_{2}$ catalyst resulting from some intermediate compounds such as benzaldehyde and benzoic acid (Huang et al. 2009).

The adsorption and oxidation rate can be highly affected by intermediates which are generating during the PCO process. High inlet concentration creates a high concentration of absorbable intermediates, influencing the overall rate of degradation and contributing to the reduction of removal efficiency (Kachina 2008, Mo et al. 2009).

The combination of advanced oxidation methods such as $\mathrm{UV} /$ Fenton, $\mathrm{UV} / \mathrm{H}_{2} \mathrm{O}_{2}$ and $\mathrm{UV} / \mathrm{O}_{3}$ are being taken into account because of abundant production of $\mathrm{OH}^{\cdot}$ radicals and the potential economic advantages (Nawrocki and Kasprzyk-Hordern 2010). The supplementation effect of the combination of UV and ozone deserves further studies (Giri et al. 2008). During UV and ozone hybrid process, strong oxidant holes and $\mathrm{OH}^{\circ}$ radicals can be generated by ozone which increases the overall efficiency and mineralization, and consequently, the final by-products can be highly reduced (QI et al. 2007).

The effect of ozone on photocatalaytic oxidation has been investigated in many studies. The results have shown that the catalyst breaks down ozone into atomic oxygen, which is a strong oxidant that causes the removal efficiency to be dramatically increased (Einaga and Futamura 2004, Sanchez et al. 1998, Zsilák et al. 2013).

The findings of our unpublished study showed that photocatalytic degradation of chloroform and chlorobenzene over expanded graphite- $\mathrm{TiO}_{2} \& \mathrm{ZnO}\left(\mathrm{EG}-\mathrm{TiO}_{2} \& \mathrm{ZnO}\right)$ Nano 
composite was a function of flow rate and concentration. The effect of the latter is especially detrimental. This is mainly due to the saturation of catalyst active sites, generation of intermediates and competitive reaction with pollutants for binding the active sites of the catalyst. The objective of this study was to investigate the effect of PCO on the removal of chloroform and chlorobenzene vapors in the presence of ozone. The effect of ozone concentration and residence time on removal efficiency was also explored. Special attention was given to the by-products and selectivity towards $\mathrm{CO}_{2}$.

\section{Material and methods}

\section{Experimental procedure and conditions}

The experimental setup is illustrated in Fig. 1. The normal air was subjected to flow through the experimental system by a compressor and filtered for contaminants and aerosols to be removed. Flow rates of $0.3,0.6$ and $1.2 \mathrm{~L} / \mathrm{min}$ were chosen for this study, corresponding to residence times of $0.4,0.2$ and 0.1 second respectively. A compact ozone generator (COG1A, ARDA, and France) producing ozone at three different concentrations of 2, 4 and $8 \mathrm{mg} / \mathrm{L}$ was used to feed the system by ozone. Chloroform and chlorobenzene were injected by a syringe pump (SP-510, JMS) in two different concentrations (250 and $500 \mathrm{ppm}$ in air). In order to provide enough mixture and prevent condensation, the air was disturbed by an electromagnet in a container $(2 \mathrm{~L})$ and at this stage the temperature was kept constant at $40^{\circ} \mathrm{C}$. After concentration equilibration, the UV lamp was turned on for 20 minutes in all experiments, and then the rate of pollutants degradation was measured.

A fixed packed-bed PCO aluminum tube reactor (inner diameter $30 \mathrm{~mm}$, length $300 \mathrm{~mm}$ ) was used. Axially, inside the reactor, an $8 \mathrm{~W}$ UV lamp of $253.7 \mathrm{~nm}$ (Philips TUV 8W G8 T5 Bulb), $15 \times 300 \mathrm{~mm}$, was placed. $100 \mathrm{~mm}$ of the reactor length was filled with $0.3 \mathrm{~g}$ of $\mathrm{EG}-\mathrm{TiO}_{2} \& \mathrm{ZnO}$ Nano composite between the outer wall of the lamp and the inner wall of the reactor so that the space around the lamp was totally packed with the composite (Fig. 2).

\section{Analytical method}

Sampling was conducted using a gastight syringe (Hamilton, United States) of embedded sampling ports before and after the PCO process. A gas chromatograph (GC-2010, Shimadzu, Japan) equipped with a hydrogen flame ionization detector (FID) and $25 \mathrm{~m}$ long SGE capillary column (fused sillica) was used to detect the contaminants at the inlet and outlet of PCO reactor. A gas chromatograph/mass spectrometer (Varian, CP-3800, United States) was also applied to determine some organic by-products. The removal efficiency of the PCO process is expressed in equation 1 .

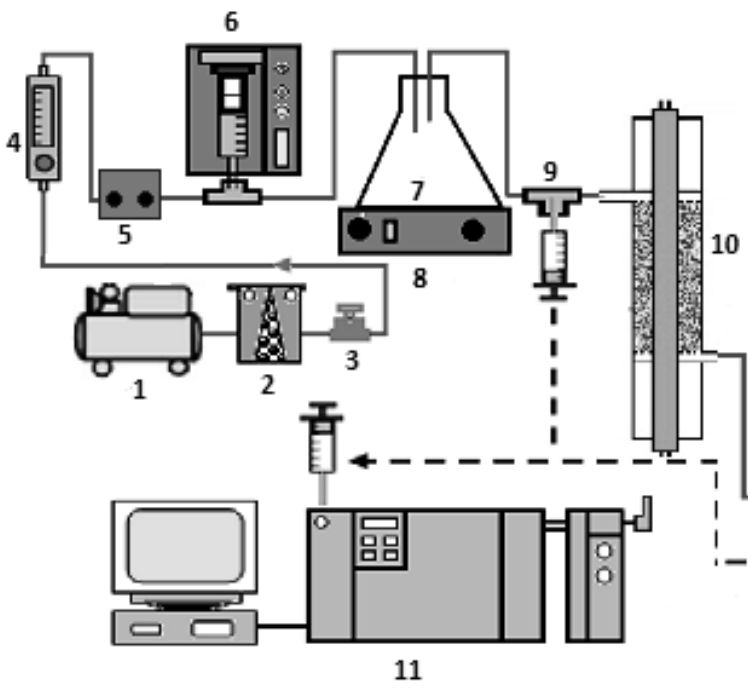

1- Compresor, 2- Adsorber (activated carbon),

3- Valve, 4- Flow meter, 5- Ozone generator,

6- Syringe pump, 7- Mixing chamber, 8- Heater

9- Sampling port, 10, Photocatalysis reactor,

11- Gas Chromatograph, 12- CO2 meter, 13-

$\mathrm{CO}$ meter, 14- Absorber (water)

Fig. 1. Schematic diagram of the experimental setup

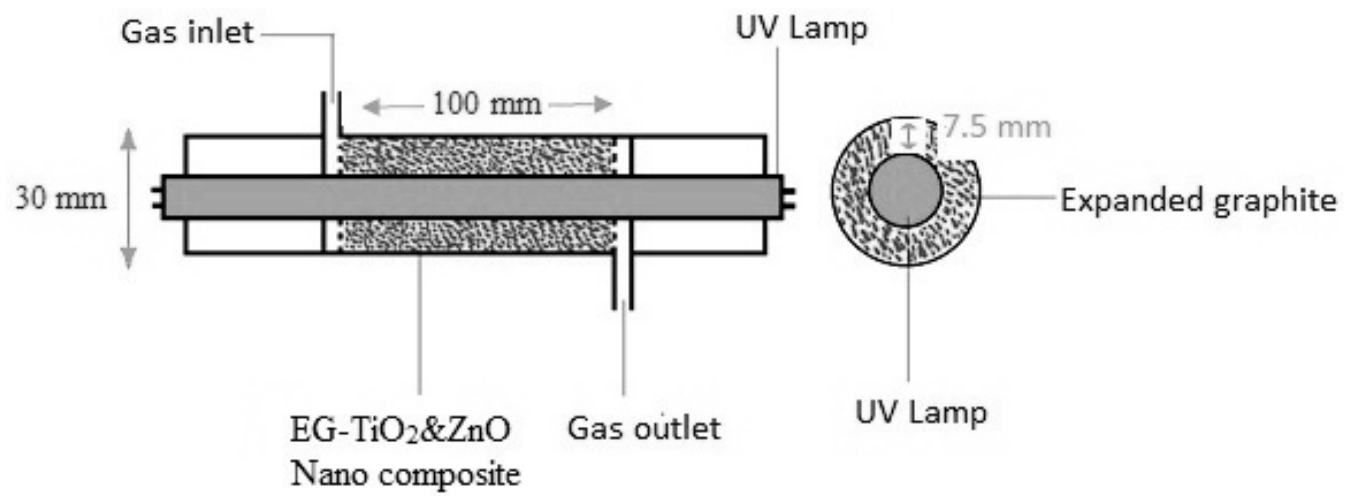

Fig. 2. Schematic overview of PCO reactor 


$$
\text { Removal efficiency }(\%)=\frac{\left(C_{i n}-C_{\text {out }}\right)}{C_{\text {in }}} \times 100 \%
$$

Where $\mathrm{C}_{\text {in }}$ and $\mathrm{C}_{\text {out }}$ are the inlet and outlet concentrations of chloroform and chlorobenzene, respectively.

$\mathrm{CO}_{2}$ produced in the reactor was monitored using a $\mathrm{CO}_{2}$ detector (Kimo-AQ100, United Kingdom). The selectivity towards $\mathrm{CO}_{2}$ for chloroform and chlorobenzene decomposition was calculated as follows:

$$
\begin{gathered}
\mathrm{SCO}_{2}=\frac{\left[\mathrm{Co}_{2}\right]}{\left(\left[C_{\text {Chloroform in }}\right]-\left[C_{\text {Chloroform out }}\right]\right)} \\
\mathrm{Co}_{2}=\frac{\left[\mathrm{Co}_{2}\right]}{6\left(\left[C_{\text {Chlorobenzene in }}\right]-\left[C_{\text {Chlorobenzene out }}\right]\right.}
\end{gathered}
$$

Where $\mathrm{C}_{\text {in }}$ and $\mathrm{C}_{\text {out }}$ are the inlet and outlet concentrations, respectively.

\section{Synthesis of EG-TiO \& ZnO Nano composite}

The EG-TiO \&ZnO Nano composite preparation technique was sol-gel. Firstly, $\mathrm{TiO}_{2}$ sol was prepared applying titaniumn-butoxide as the precursor. $2.04 \mathrm{ml}$ of $\mathrm{Ti}(\mathrm{OBu})_{4}$ diluted with $36.64 \mathrm{ml}$ of $\mathrm{PrOH}$ as a solvent. Then, the resultant mixture was stirred at room temperature for $1 \mathrm{~h}$. Afterwards, acetyl acetone as stabilizer was added dropwise to the mixed solution under stirring and the solution was stirred again for $2 \mathrm{~h}$. Then, a $\mathrm{HNO}_{3}$ aqueous solution was added under stirring, ensuring a $\mathrm{pH}$ of about 2. Finally, the solution was refluxed for $8 \mathrm{~h}$ to obtain crystalline anatase sol (Yan and Chunwei 2006, Shahna et al, 2015, Shahna et al, 2016).

To prepare $\mathrm{ZnO}$ sol, $8.76 \mathrm{~g}$ zinc acetate dehydrate was dissolved in $200 \mathrm{ml}$ of ethanol. Next, $5.96 \mathrm{~g}$ of Tri Ethanol Amine was added to the solution. After one h, the solution was removed and ultrasonically treated for $30 \mathrm{~min}$ at $40^{\circ} \mathrm{C}(\mathrm{Pal}$ and Sharon 2002) (Shahna et al. 2015, Shahna et al. 2016).

The $\mathrm{TiO}_{2}$ and $\mathrm{ZnO}$ sols were combined in equal amounts. Using a thermal shock method (thermal shock in the range of $1000-1050^{\circ} \mathrm{C}$ for 30 seconds), the expandable graphite (Beijing invention biology engineering \& new materials,
China) converted to the expanded graphite. The expanded graphite was then added to the combined sol and placed in a dark room for two days. The smooth and dried samples were then calcined in an oven $\left(400^{\circ} \mathrm{C}\right.$ for $2 \mathrm{~h}$ ) (Shahna et al. 2015, Shahna et al. 2016).

\section{Characterizations}

The properties of the synthesized $\mathrm{EG}-\mathrm{TiO}_{2} \& \mathrm{ZnO}$ Nano composite have been identified through different analytical techniques. The morphologies and microstructures of Nano composite were observed using SEM (TESCAN, MIRA3, unites state). XRD analysis was carried out over the 2-theta range of $2-90^{\circ}$ with APD 2000 XRD (Italy) using CU radiation $\left(1.54 \mathrm{~A}^{\circ}\right)$ for crystal phase identification of Nano composite. In order to measure the elements in Nano composite, EDX technique was applied.

\section{Results and discussion}

\section{Characteristics of EG-TiO2\&ZnO Nano composite}

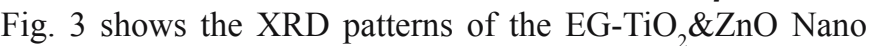
composite after heat treatment at $400{ }^{\circ} \mathrm{C}$ for $2 \mathrm{~h}$. It is evident from the figure that the only detected phase for $\mathrm{TiO}_{2}$ was anatase, and no rutile and brookite phases were observed. As it has been described in the literature, the anatase phase formed below $500^{\circ} \mathrm{C}$ transforms to a rutile-type structure above $600^{\circ} \mathrm{C}$ and is changed into single phase of rutile at $700 \sim 900^{\circ} \mathrm{C}$ (Inagaki et al. 2003, Chen et al. 2006a, Oh et al. 2010, Chen et al. 2006b). Major peaks for $\mathrm{TiO}_{2}$ particles were detected at 2-theta degrees of $25.2^{\circ}, 38.5^{\circ}, 53.8^{\circ}, 62.6^{\circ}, 68.7^{\circ}$ and $76.0^{\circ}$. They were all assigned to diffraction peaks of the anatase $\mathrm{TiO}_{2}$ (JCPDS No.21-1272).

For $\mathrm{ZnO}$ samples as shown in Fig. 3, major peaks were detected at 2-theta degrees of $31.7^{\circ}, 34.4^{\circ}, 36.2^{\circ}, 47.5^{\circ}$, $56.6^{\circ}, 67.9^{\circ}$ and $89.6^{\circ}$ which all were assigned to diffraction peaks of the $\mathrm{ZnO}$ (JCPDS No.70-2551). All diffraction peaks correspond to the standard diffraction pattern except for $2 \theta=26.5^{\circ}$ which is related to the EG itself ( $\mathrm{Wu}$ et al. 2011). This most intense peak of the template overlapped strongly the anatase $\mathrm{TiO}_{2}$ refractogram at $2 \theta$ of $25.2^{\circ}$.

SEM observations confirmed the results of the XRD analysis. It showed that both $\mathrm{TiO}_{2}$ and $\mathrm{ZnO}$ particles have been

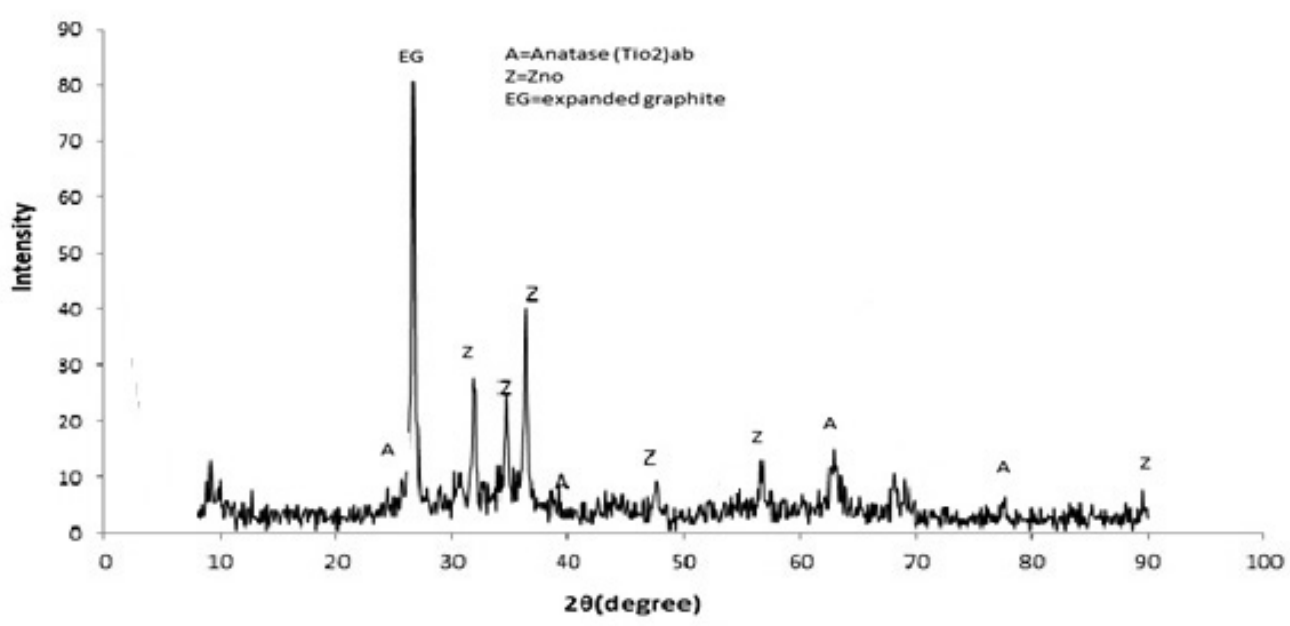

Fig. 3. XRD patterns of the $\mathrm{EG}_{-} \mathrm{TiO}_{2} \& \mathrm{ZnO}$ Nano composite 
coated on the surface of EG. Fig. 4 represents the SEM images of the EG loaded by $\mathrm{TiO}_{2}$ and $\mathrm{ZnO}$. It was clearly seen that the EG structure was changed and broken up to small fragments. It was also seen that $\mathrm{TiO}_{2}$ and $\mathrm{ZnO}$ particles were effectively spread on the surface of the EG layers as single or multi-layer. The Nano metric scale of $\mathrm{TiO}_{2}$ and $\mathrm{ZnO}$ particles is evident from the figures. It is also seen that the size of $\mathrm{ZnO}$ particles (Square shape) are larger than that of $\mathrm{TiO}_{2}$ particles (spherical shape). The larger size of $\mathrm{ZnO}$ particles can be the result of agglomeration (Carp et al. 2004).

Table. 1 shows the EDX elemental microanalysis (wt $\%$ and $\mathrm{At} \%$ ) of $\mathrm{EG}-\mathrm{TiO}, \& \mathrm{ZnO}$ Nano composite. The data showed that $\mathrm{EG}-\mathrm{TiO}_{2} \& \mathrm{ZnO}$ Nano composite contained four kinds of main elements, $\mathrm{C}, \mathrm{O}, \mathrm{Ti}$ and $\mathrm{Zn}$. It is obvious that $\mathrm{wt} \%$ $(26.86 \%)$ of Ti was much more than of $\mathrm{Zn} \mathrm{wt} \%(12.11 \%)$ in the EG-TiO $\& \mathrm{ZnO}$ Nano composite and the catalyst was coated by $\mathrm{TiO}_{2}$ much more than $\mathrm{ZnO}$ particles. These phenomena may be the consequence of smaller size of $\mathrm{TiO}_{2}$ nanocrystals.

\section{Destruction of chloroform and chlorobenzene}

Chloroform and chlorobenzene were degraded in $\mathrm{O}_{3}-\mathrm{PCO}$ processes. The removal efficiency, as a function of initial flow rate, ozone and pollutant (Chloroform and Chlorobenzene) concentrations, has been shown in Fig. 5.

Best efficiency of the photocatalyst occurred at high concentrations of the pollutant. In order to increase the concentration of pollutant close to the catalyst surface, researchers have employed an adsorbent as a support ( $\mathrm{Lu}$ et al. 2012). The results of the present study demonstrated that chloroform and chlorobenzene destruction efficiency was a function of the inlet concentration and significantly increased when the pollutants feeding was raised. For chloroform, by raising the concentration from 250 to $500 \mathrm{ppm}$, the efficiency went up by $6 \%, 8 \%$ and $4 \%$ at flow rates of $0.3,0.6$ and $1.2 \mathrm{~L} / \mathrm{min}$, respectively. These findings showed that destruction efficiency was reduced with increasing concentrations. This can be attributed to saturation of the catalyst active sites by the pollutants and production of more intermediates at high concentrations. PCO reaction is divided into several more minor reactions that follow each other, the reaction products of each of these steps are called intermediate. These intermediates may be placed on the active sites and disrupt the PCO process (Mo et al. 2009).

There were multiple processes in photocalaytic ozonation system, including $\mathrm{PCO}$, ozone photolysis $\left(\mathrm{UV} / \mathrm{O}_{3}\right)$, and catalytic ozonation $\left(\mathrm{O}_{3} / \mathrm{EG}-\mathrm{TiO}_{2} \& \mathrm{ZnO}\right)$. In $\mathrm{O}_{3}$-PCO process, chloroform and chlorobenzene oxidation occurred not only on the surface of photocatalyst (e.g., in the PCO and

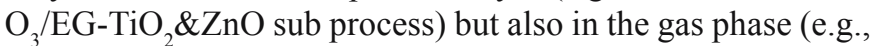
$\mathrm{UV} / \mathrm{O}_{3}$ ) (Huang, 2010). In addition, the presence of ozone increased the active species $\left(\mathrm{OH}^{*}, \mathrm{O}^{*}\right)$. Eq. 4 shows that the pathway of $\mathrm{OH}^{\cdot}$ radicals are the dominant strong oxidant in the PCO process. Equations 5 and 6 show the pathway of

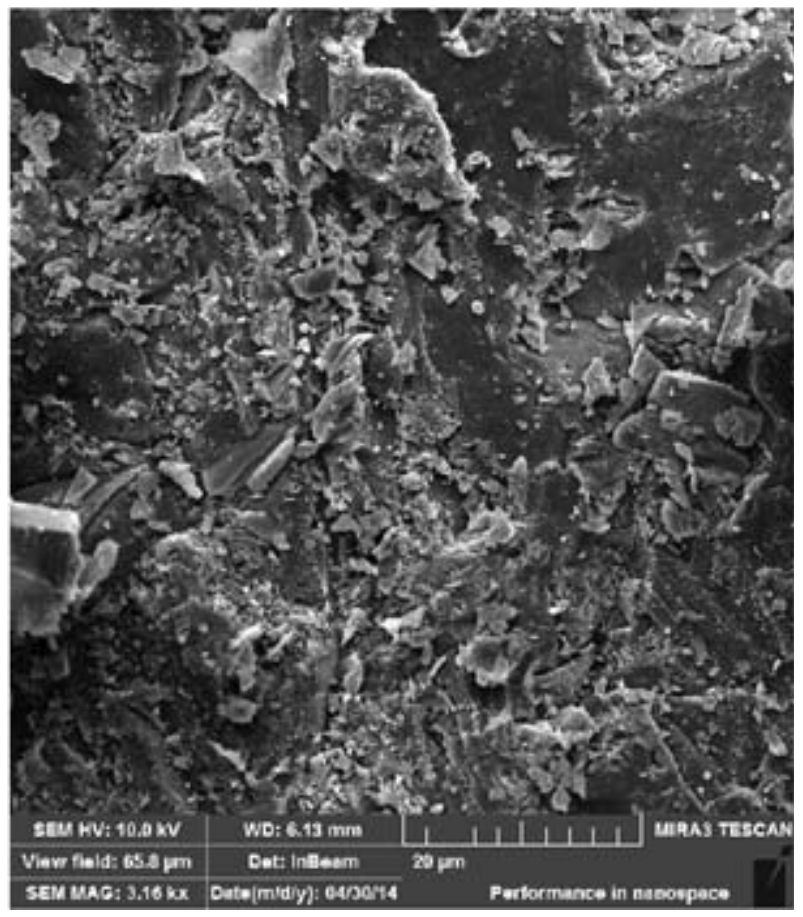

Fig. 4. The SEM micrograph of EG-TiO2\&ZnO Nano composite: efficiency in nanospace $20 \mu \mathrm{m}$

Table. 1. EDX Elemental Microanalysis (wt\% and At\%) of the EG-TiO 2 ZnO Nano composite

\begin{tabular}{|c|c|c|c|c|c|c|}
\hline \multicolumn{7}{|c|}{ Elements } \\
\hline & C & O & Ti & Zn & Others & Total \\
\hline $\mathbf{W t} \%$ & 45.54 & 13.62 & 26.86 & 12.11 & 1.87 & 100 \\
\hline At\% & 68.93 & 15.45 & 9.98 & 3.86 & 1.78 & 100 \\
\hline
\end{tabular}


additional oxidant agents $\left(\mathrm{O}^{*}, \mathrm{OH}^{\circ}\right)$ formation in the $\mathrm{O}_{3}-\mathrm{PCO}$ system (Huang 2010).

$$
\begin{gathered}
3 e^{-}+3 h^{+}+2 \mathrm{H}_{2} \mathrm{O}+\mathrm{O}_{2} \rightarrow 4 \mathrm{OH}^{\cdot} \\
\mathrm{O}_{3} \rightarrow \mathrm{O}^{\cdot}+\mathrm{O}_{2} \\
\mathrm{O}_{3}+\mathrm{H}_{2} \mathrm{O} \rightarrow 2 \mathrm{OH}^{\cdot}+\mathrm{O}_{2}
\end{gathered}
$$

Therefore, in the $\mathrm{O}_{3}-\mathrm{PCO}$ system, two degradation processes are added to the $\mathrm{PCO}$ and more hydroxyl radicals and atomic oxygen are created which are considered as strong oxidants. Given these changes in $\mathrm{O}_{3}-\mathrm{PCO}$ system, the likelihood of the saturation of active sites of the catalyst is reduced. The generated intermediates are also oxidized and removed from the catalyst surface; hence, more active sites of the catalyst are exposed to the pollutants and the removal efficiency increases by raising the inlet concentration.

The results showed that the degree of removal of the chloroform was much higher than that of chlorobenzene, explaining difference in the chemical structure of these compounds. With regard to the chemical structure of the compounds and, in fact, the quantity of required energy for breaking of each band, (Karatum 2012), the degradation of chlorobenzene was much more energetic; the chloroform removal efficiency therefore was much higher.

Fig. 6 shows the increased level of removal efficiency in the $\mathrm{O}_{3}$-PCO hybrid system relative to $\mathrm{PCO}$ alone. As can be seen, the rate of increase for the concentrations of $500 \mathrm{ppm}$ was greater than that of $250 \mathrm{ppm}$ resulting from the saturation behavior of the PCO alone. However, with $\mathrm{O}_{3}$-PCO hybrid process, due to a rise in the generation of oxidizing agents, optimal concentration is increased and therefore by raising the concentration the removal efficiency is maximized.

According to previous works, the removal rate of contaminants is decreased by increasing the flow rate, particularly at low concentrations (Lu et al. 2012). Our results were supported by the literature, indicating that the increase of flow rate leads to higher removal efficiency. For example, the chloroform removal efficiency went up from 3 to $13 \%$ when the flow rate increased from 0.3 to 0.6 and then to $1.2 \mathrm{~L} / \mathrm{min}$. At the same time, for chlorobenzene, the removal efficiency increased from 7 to $11 \%$. The effect of flow rate on removal efficiency in this study can mainly be attributed to the more amount of ozone introduced to the reactor. The concentrations of the ozone introduced to the reactor at flow rates of $0.3,0.6$ and $1.2 \mathrm{~L} / \mathrm{min}$ were 2,4 and $8 \mathrm{mg} / \mathrm{L}$ respectively. Going up the concentration of the introduced ozone leads to higher removal efficiency through generating more active species such as $\mathrm{O}^{*}$, $\mathrm{OH}^{*}$ (Huang 2010).

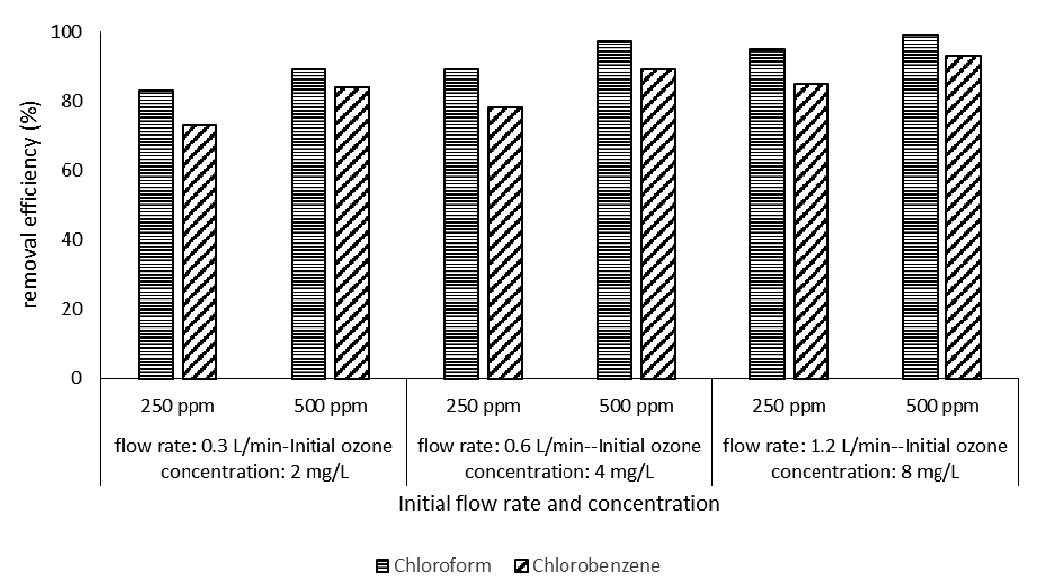

Fig. 5. Removal efficiency of chloroform and chlorobenzene

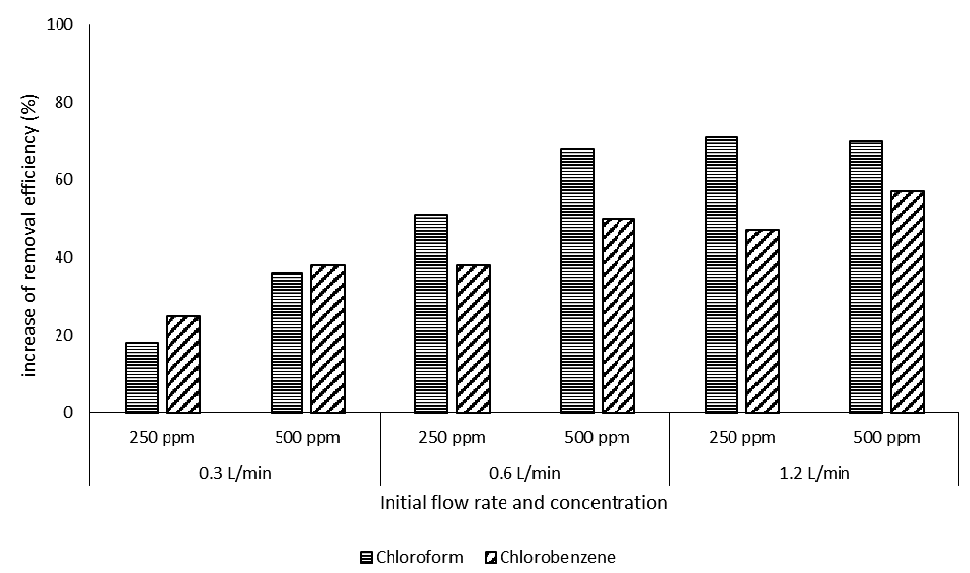

Fig. 6. Increase the removal efficiency of chloroform and chlorobenzene by $\mathrm{O}_{3}-\mathrm{PCO}$ relation to PCO 
According to the literature, increasing the flow rate raises the space velocity and thereby reduces the degradation efficiency. However, in this study, increasing the ozone concentration was much effective than the space velocity. It can be clearly seen from figure 7 that the removal efficiency of $\mathrm{O}_{3}$-PCO combined system increased much more than that of PCO alone when the flow rate raised up.

\section{$\mathrm{CO}_{2}$ selectivity and byproducts}

The catalytic ozonation is an effective method for destruction of VOCs. From the advantages of this method conversion of VOCs into less harmful materials such as water and carbon dioxide can be noted (Rezaei and Soltan 2012). Einaga and Futamura (2007), conducted a study and tried to determine the products of catalytic ozonation of benzene, and concluded that $\mathrm{CO}_{2}$ and $\mathrm{CO}$ were the predominant reaction products.

The $\mathrm{CO}_{2}$ selectivity declined with increasing the flow rate and introduced concentration (Fig. 7). This reduction was greater for chlorobenzene. Although increasing the flow rate increased the generated oxidants of ozone, the residence time of contaminants in the reactor declined and as a consequence there would be not enough time for the completion of oxidation and mineralization reactions. Therefore, the pollutants were just converted to intermediates and not the final products like $\mathrm{CO}_{2}$.
In order to explain the lesser $\mathrm{CO}_{2}$ selectivity of chlorobenzene compared to chloroform, the three following causes would be noted: 1 - chlorobenzene is more difficult to be degraded due to the aromatic ring which has less reactivity, 2 - intermediate compounds are generated in destruction process of chlorobenzene compared to chloroform, 3 - chlorobenzene requires higher amounts of oxidants than chloroform for oxidation (Huang 2010). Assuming production of $\mathrm{CO}_{2}, \mathrm{H}_{2} \mathrm{O}$, and $\mathrm{CL}$, the complete oxidation of a $\mathrm{CHCL}_{3}$ molecule requires $5 \mathrm{OH}^{\bullet}$ molecules or $5 / 2 \mathrm{O}^{*}$ molecules, whereas the figures for the complete oxidation of a chlorobenzene molecule rises up to $29 \mathrm{OH}^{\circ}$ or $29 / 2 \mathrm{O}^{\circ}$ as described in equations $7-10$.

$$
\begin{gathered}
5 \mathrm{OH}^{\cdot}+\mathrm{CHCL}_{3} \rightarrow \mathrm{CO}_{2}+3 \mathrm{H}_{2} \mathrm{O}+3 \mathrm{CL} \\
5 \mathrm{O}^{\circ}+2 \mathrm{CHCL}_{3} \rightarrow 2 \mathrm{CO}_{2}+\mathrm{H}_{2} \mathrm{O}+6 \mathrm{CL} \\
29 \mathrm{OH}^{\cdot}+\mathrm{C}_{6} \mathrm{H}_{5} \mathrm{CL}+17 \mathrm{H}_{2} \mathrm{O}+\mathrm{CL} \\
29 \mathrm{O}^{\circ}+2 \mathrm{C}_{6} \mathrm{H}_{5} \mathrm{CL} \rightarrow 12 \mathrm{CO}_{2}+5 \mathrm{H}_{2} \mathrm{O}+2 \mathrm{CL}
\end{gathered}
$$

Although the degradation efficiency is raised with increasing the concentration, the oxidant agents' levels

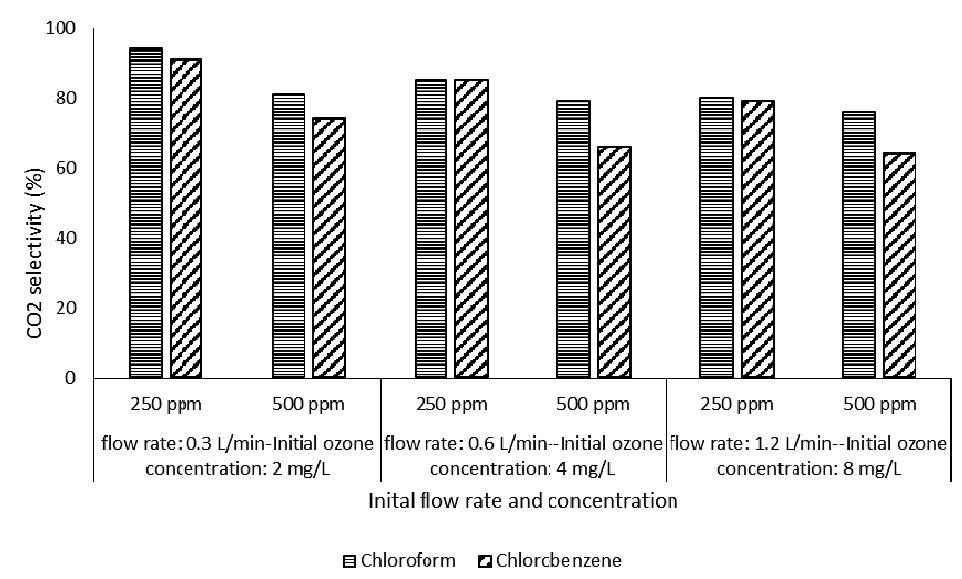

Fig. 7. $\mathrm{CO}_{2}$ selectivity of Chloroform and Chlorobenzene

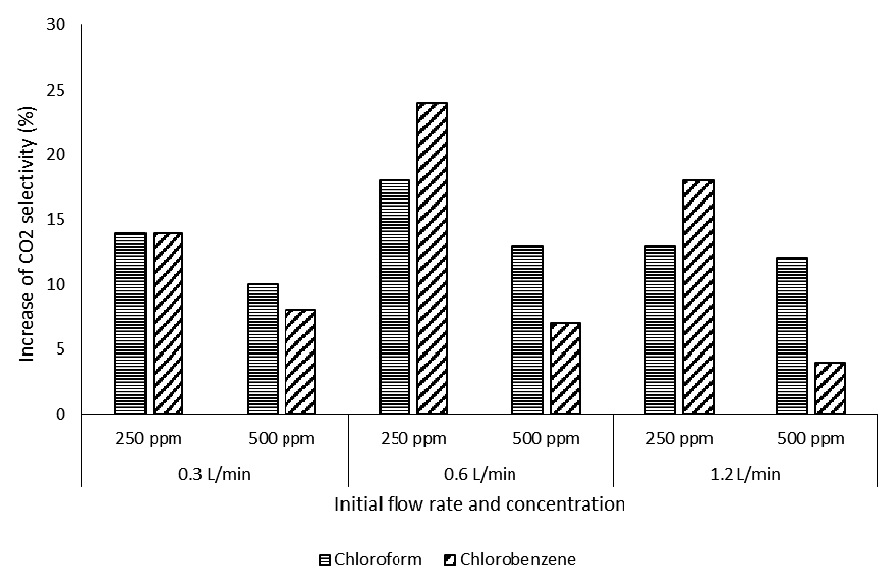

Fig. 8. Increase the $\mathrm{CO}_{2}$ selectivity of chloroform and chlorobenzene by $\mathrm{O}_{3}-\mathrm{PCO}$ process toward PCO process 
are not sufficient to guarantee complete oxidation and the chemicals are just converted to intermediates. Fig. 8 shows the amount of increased selectivity of $\mathrm{CO}_{2}$ by the hybrid system compared to the PCO process. The results showed that the selectivity patterns of chloroform and chlorobenzene were not similar. The increase level for chloroform and chlorobenzene was similar at flow rates of $0.3 \mathrm{~L} / \mathrm{min}$ and concentration of $250 \mathrm{ppm}$. However, at this flow rate with climbing up the concentration, the $\mathrm{CO}_{2}$ selectivity for chloroform decomposition increased. At flow rates of 0.6 and $1.2 \mathrm{~L} / \mathrm{min}$, raising the concentration had a little effect on increasing the $\mathrm{CO}_{2}$ selectivity of chloroform, while the selectivity of $\mathrm{CO}_{2}$ for chlorobenzene was induced significantly mainly due to the deficiency of oxidant agents for the complete oxidation of chlorobenzene.

\section{Conclusion}

Chloroform and chlorobenzene degradation under environmental indoor conditions was achieved by photocatalytic oxidation combined with ozone. From a removal efficiency point of view, the combined system led to better removal efficiency compared to PCO alone.

In this study the effect of raising the introduced ozone concentration versus increasing the resident time was investigated. The results showed that raising the introduced ozone concentration and generating more reactive species, has a greater effect on the removal efficiency than for increasing the residence time. The removal efficiency therefore went up with increasing the flow rate which was accompanied by the introduced ozone concentration. The results showed that the removal efficiency increased with raising the introduced concentration. This is mainly due to oxidation of the intermediate compounds and adsorbed pollutants on the active sites of catalyst by additional oxidant agents generated through ozone feeding, resulting in regenerating the catalyst active sites. Therefore, the catalyst showed saturation behavior at higher concentrations and consequently the removal efficiency increased.

From a mineralization point of view, the selectivity of $\mathrm{CO}_{2}$ in the combined system increased by about $13 \%$ in comparison to photocatalytic oxidation alone. This is generally due to generation of more oxidant agents in combined system, leading to higher mineralization of pollutants yielding $\mathrm{CO}_{2}$ and $\mathrm{H}_{2} \mathrm{O}$. Increasing the residence time had a greater effect on the selectivity of $\mathrm{CO}_{2}$ than the introduced ozone concentration. Although raising the pollutants concentration leads to higher removal efficiency, the perfect mineralization of compounds is not implemented in high concentrations. Based on these results, the combined system is highly preferred due to higher removal efficiency, complete mineralization and the formation of lower amounts of harmful byproducts.

\section{References}

Carp, O., Huisman, C.L. \& Reller, A. (2004). Photoinduced reactivity of titanium dioxide, Progress in solid state chemistry, 32, 1, pp. 33-177.

Chen, M.L., Bae, J.S. \& Oh, W.C. (2006a). Preparation of carbon-coated $\mathrm{TiO}_{2}$ at different heat treatment temperature and their photoactivity, Carbon Sciences, 7, pp. 259-265.
Chen, M., Bae, J. \& Oh, W. (2006b). Photocatalytic effect for the carbon-coated $\mathrm{TiO}_{2}$ prepared from different heat treatment temperature, Analytical Science \& Technology, 19, 6, pp. 460-467.

Einaga, H. \& Futamura, S. (2004). Catalytic oxidation of benzene with ozone over alumina-supported manganese oxides, Journal of Catalysis, 227, 2, pp. 304-312.

Einaga, H. \& Futamura, S. (2007). Catalytic oxidation of benzene with ozone over $\mathrm{Mn}$ ion-exchanged zeolites, Catalysis Communications, 8, 3, pp. 557-560.

Giri, R.R., Ozaki, H., Takanami, R. \& Taniguchi, S. (2008). A novel use of $\mathrm{TiO}_{2}$ fiber for photocatalytic ozonation of 2 , 4-dichlorophenoxyacetic acid in aqueous solution, Journal of Environmental Sciences, 20, 9, pp. 1138-1145.

Huang, H. (2010). Removal of air pollutants by photocatalysis with ozone in a continuous-flow reactor, Environmental Engineering Science, 27, 8, pp. 651-656.

Huang, X., Yuan, J., Shi, J. \& Shangguan, W. (2009). Ozone-assisted photocatalytic oxidation of gaseous acetaldehyde on $\mathrm{TiO}_{2} / \mathrm{H}-Z \mathrm{SM}-5$ catalysts, Journal of Hazardous Materials, 171, 1, pp. 827-832.

Inagaki, M., Hirose, Y., Matsuaga, T., Tsumura, T. \& Toyoda, M. (2003). Carbon coating of anatase-type $\mathrm{TiO}_{2}$ through their precipitation in PVA aqueous solution, Carbon, 41, 13, pp. 2619-2624.

Kachina, A. (2008). Gas-phase photocatalytic oxidation of volatile organic compounds, $\mathrm{PhD}$ Thesis, Lappeenranta University of Technology, Lappeenranta 2008.

Karatum, O. (2012). Treatment of low concentrations of volatile organic compounds by non-thermal plasma, MSc Thesis, Department of civil and environmental engineering, Duke University, Durham, North Carolina, United States 2012.

Liu, J.H., Yang, R. \& Li, S.M. (2006). Preparation and application of efficient $\mathrm{TiO}_{2} / \mathrm{ACF}$ s photocatalyst, Journal of Environmental Sciences, 18, 5, pp. 979-982.

Lu, Y., Wang, D., Wu, Y., Ma, C., Zhang, X. \& Yang, C. (2012). Synergistic effect of nanophotocatalysis and nonthermal plasma on the removal of indoor HCHO, International Journal of Photoenergy, 2012, pp. 1-8.

Mo, J., Zhang, Y., Xu, Q., Lamson, J.J. \& Zhao, R. (2009). Photocatalytic purification of volatile organic compounds in indoor air: a literature review, Atmospheric Environment, 43, 14, pp. 2229-2246.

Nawrocki, J. \& Kasprzyk-Hordern, B. (2010). The efficiency and mechanisms of catalytic ozonation, Applied Catalysis B: Environmental, 99, 1, pp. 27-42.

Oh, W.C., Choi, J.G., Zhang, F.J., Go, Y.G. \& Chen, M.L. (2010). Synthesis of expanded graphite-titanium oxide composite and its photocatalytic performance, Journal of the Korean Ceramic Society, 47, 3, pp. 210-215.

Pal, B. \& Sharon, M. (2002). Enhanced photocatalytic activity of highly porous $\mathrm{ZnO}$ thin films prepared by sol-gel process, Materials Chemistry and Physics, 76, 1, pp. 82-87.

Qi, H., Sun, D.Z. \& Chi, G.Q. (2007). Formaldehyde degradation by $\mathrm{UV} / \mathrm{TiO}_{2} / \mathrm{O}_{3}$ process using continuous flow mode, Journal of Environmental Sciences, 19, 9, pp. 1136-1140.

Rezaei, E. \& Soltan, J. (2012). Low temperature oxidation of toluene by ozone over $\mathrm{MnO}_{\mathrm{x}} / \gamma$-alumina and $\mathrm{MnO}_{\mathrm{x}} / \mathrm{MCM}-41$ catalysts, Chemical Engineering Journal, 198-199, pp. 482-490.

Sanchez, L., Peral, J. \& Domenech, X. (1998). Aniline degradation by combined photocatalysis and ozonation, Applied Catalysis B: Environmental, 19, 1, pp. 59-65.

Shahna, F.G., Bahrami, A., Alimohammadi, I., Yarahmadi, R., Jaleh, B., Gandomi, M., Ebrahimi, H. \& Abedi, K.A.D. (2016). Chlorobenzene degeradation by non-thermal plasma combined with $\mathrm{EG}-\mathrm{TiO}_{2} / \mathrm{ZnO}$ as a photocatalyst: Effect of photocatalyst on $\mathrm{CO}_{2}$ selectivity and byproducts reduction, Journal of Hazardous Materials, 324, pp. 544-553. 
Shahna, F.G., Ebrahimi, H., Jaleh, B. \& Bahrami, A. (2015). Decomposition of gas-phase chloroform using nanophotocatalyst downstream the novel non-thermal plasma reactor: by-products elimination. International Journal of Environmental Science and Technology, 12, 11, pp. 3489-3498.

Verma, A., Kaur, H. \& Dixit, D. (2013). Photocatalytic, sonolytic and sonophotocatalytic degradation of 4-chloro-2-nitro phenol. Archives of Environmental Protection, 39, 2, pp. 17-28.

Wu, C., Zhang, Y., Li, S., Zheng, H., Wang, H., Liu, J., Li, K. \& Yan, H. (2011). Synthesis and photocatalytic properties of the graphene- $\mathrm{La}_{2} \mathrm{Ti}_{2} \mathrm{O}_{7}$ nanocomposites, Chemical Engineering Journal, 178, pp. 468-474.

Yan, H. \& Chunwel, Y. (2006). Low-temperature preparation of photocatalytic $\mathrm{TiO} 2$ thin films on polymer substrates by direct deposition from anatase sol, Journal of Materials Science and Technology, 22, 2, pp. 239-244,

Zsilak, Z., Szabo-Bardos, E., Fonagy, O., Horvath, O., Horvath, K. \& Hajos, P. (2013). Degradation of benzenesulfonate by heterogeneous photocatalysis combined with ozonation, Catalysis Today, 230, pp. 55-60. 